\title{
Multiple positive solutions of nonlinear BVPs for differential systems involving integral conditions
}

\section{Hai-E Zhang*}

\section{"Correspondence: \\ haiezhang@126.com Department of Basic Science, \\ Tangshan College, Tangshan, Hebei 063000, People's Republic of China}

\begin{abstract}
In this paper, we consider the following system of nonlinear third-order nonlocal boundary value problems (BVPs for short):

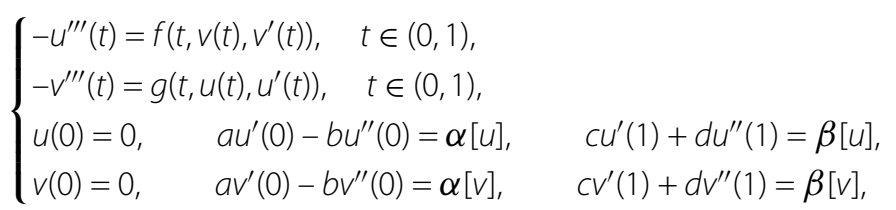

where $f, g \in C\left([0,1] \times R^{+} \times R^{+}, R^{+}\right), \alpha[u]=\int_{0}^{1} u(t) d A(t)$ and $\beta[u]=\int_{0}^{1} u(t) d B(t)$ are linear functionals on $C[0,1]$ given by Riemann-Stieltjes integrals and are not necessarily positive functionals; $a, b, c, d$ are nonnegative constants with $\rho:=a c+a d+b c>0$. By using the Guo-Krasnoselskii fixed point theorem, some sufficient conditions are obtained for the existence of at least one or two positive solutions and nonexistence of positive solutions to the above problem. Two examples are also included to illustrate the main results.
\end{abstract}

MSC: $34 \mathrm{~B} 15$

Keywords: differential system; multiple positive solution; integral conditions

\section{Introduction}

The theory of BVPs with integral boundary conditions for ordinary differential equations arises in different areas of applied mathematics and physics. For example, heat conduction, chemical engineering, underground water flow, thermo-elasticity, and plasma physics can be reduced to nonlocal problems with integral boundary conditions. Moreover, BVPs with Riemann-Stieltjes integral boundary condition (BC for short) have been considered recently as both multipoint and Riemann integral type BCs are treated in a single framework. For more comments on Stieltjes integral BC and its importance, we refer the reader to the papers by Webb and Infante [1-3] and their other related works.

In recent years, third-order nonlocal BVPs have received much attention from many authors; see, for example [4-14]. It is worth mentioning that Sun and Li [12] studied the

\section{黛 Springer}

๑2014 Zhang; licensee Springer. This is an Open Access article distributed under the terms of the Creative Commons Attribution License (http://creativecommons.org/licenses/by/2.0), which permits unrestricted use, distribution, and reproduction in any medium, provided the original work is properly cited. 
third-order BVP with integral boundary conditions

$$
\left\{\begin{array}{l}
u^{\prime \prime \prime}(t)+f\left(t, u(t), u^{\prime}(t)\right)=0, \quad 0<t<1, \\
u(0)=u^{\prime}(0)=0, \quad u^{\prime}(1)=\int_{0}^{1} g(t) u^{\prime}(t) d t .
\end{array}\right.
$$

Their main tool was the Guo-Krasnoselskii fixed point theorem. Recently, we [14] were concerned with the existence of a monotone positive solution for the third-order BVP

$$
\left\{\begin{array}{l}
u^{\prime \prime \prime}(t)+f\left(t, u(t), u^{\prime}(t)\right)=0, \quad 0<t<1 \\
u(0)=0 \\
a u^{\prime}(0)-b u^{\prime \prime}(0)=\alpha[u] \\
c u^{\prime}(1)+d u^{\prime \prime}(1)=\beta[u]
\end{array}\right.
$$

by applying monotone iterative techniques, where $f \in C\left([0,1] \times R^{+} \times R^{+}, R^{+}\right), \alpha[u]=$ $\int_{0}^{1} u(t) d A(t)$ and $\beta[u]=\int_{0}^{1} u(t) d B(t)$ are linear functionals on $C[0,1]$ given by RiemannStieltjes integrals.

Furthermore, motivated by the wide applications of systems of differential equations in biomathematics, the study of systems of BVPs has received increased interest; see [15-28] and the references therein. In particular, Henderson and Luca [17] established the existence of positive solutions for the system of BVPs with multi-point boundary conditions

$$
\left\{\begin{array}{l}
-u^{\prime \prime}(t)+\lambda c(t) f(u(t), v(t))=0, \quad t \in(0, T), \\
-v^{\prime \prime}(t)+\mu d(t) g(u(t), v(t))=0, \quad t \in(0, T), \\
\alpha u(0)-\beta u^{\prime}(0)=0, \quad u(T)=\sum_{i=1}^{m-2} a_{i} u\left(\xi_{i}\right), \quad m \geq 3, \\
\gamma v(0)-\delta v^{\prime}(0)=0, \quad v(T)=\sum_{i=1}^{n-2} b_{i} v\left(\eta_{i}\right), \quad m \geq 3
\end{array}\right.
$$

by applying the fixed point index theory.

Yang [27] studied the existence of positive solutions for the system of second-order nonlocal BVPs

$$
\left\{\begin{array}{l}
-u^{\prime \prime}(t)=f(t, u, v) \\
-v^{\prime \prime}(t)=g(t, u, v) \\
u(0)=v(0)=0 \\
u(1)=H_{1}\left(\int_{0}^{1} u(\tau) d \alpha(\tau)\right) \\
v(1)=H_{2}\left(\int_{0}^{1} v(\tau) d \beta(\tau)\right)
\end{array}\right.
$$

by using fixed point index theory in a cone.

Infante and Pietramala [19] studied the existence of positive solutions for a system of perturbed Hammerstein integral equations by fixed point index theory for compact maps and illustrated their theory by studying the following system of BVPs:

$$
\begin{cases}u^{\prime \prime}(t)+g_{1}(t) f_{1}(t, u(t), v(t))=0, & 0<t<1 \\ v^{\prime \prime}(t)+g_{2}(t) f_{2}(t, u(t), v(t))=0, & 0<t<1 \\ u(0)=H_{11}\left(\beta_{11}[u]\right), & u(1)=H_{12}\left(\beta_{12}[u]\right) \\ v(0)=H_{21}\left(\beta_{21}[v]\right), & v^{\prime}(1)=H_{22}\left(\beta_{22}[v]\right) .\end{cases}
$$


The result was quite general and covered a wide class of systems of BVPs. Here $\beta_{i j}[w]$ was of the form $\beta_{i j}[w]=\int_{0}^{1} w(t) d B_{i j}(t)$ involving positive Riemann-Stieltjes measures.

Inspired greatly by the above-mentioned excellent works, in this paper, we are concerned with the following system of third-order BVPs:

$$
\left\{\begin{array}{l}
-u^{\prime \prime \prime}(t)=f\left(t, v(t), v^{\prime}(t)\right), \quad t \in(0,1), \\
-v^{\prime \prime \prime}(t)=g\left(t, u(t), u^{\prime}(t)\right), \quad t \in(0,1), \\
u(0)=0, \quad a u^{\prime}(0)-b u^{\prime \prime}(0)=\alpha[u], \quad c u^{\prime}(1)+d u^{\prime \prime}(1)=\beta[u], \\
v(0)=0, \quad a v^{\prime}(0)-b v^{\prime \prime}(0)=\alpha[v], \quad c v^{\prime}(1)+d v^{\prime \prime}(1)=\beta[v],
\end{array}\right.
$$

where $f, g \in C\left([0,1] \times R^{+} \times R^{+}, R^{+}\right), \alpha[u]=\int_{0}^{1} u(t) d A(t)$ and $\beta[u]=\int_{0}^{1} u(t) d B(t)$ are linear functionals on $C[0,1]$ given by Riemann-Stieltjes integrals with signed measures; $a, b, c$, $d$ are nonnegative constants with $\rho:=a c+a d+b c>0$. To the best of our knowledge, the study of existence of positive solutions of third-order differential systems (1.6) has not been done.

A vector $(u, v) \in C^{2}(0,1) \times C^{2}(0,1)$ is said to be a positive solution of BVP (1.6) if and only if $u, v$ satisfy BVP $(1.6)$ and $u, v$ are positive on $(0,1)$. The proof of our main results is based on the well-known Guo-Krasnoselskii fixed point theorem, which we present now.

Theorem 1.1 Let $E$ be a Banach space, $K \subset E$ be a cone, and $\Omega_{1}$ and $\Omega_{2}$ be bounded open subsets of $E$ with $0 \in \Omega_{1}, \bar{\Omega}_{1} \subset \Omega_{2}$. Assume that $A: K \cap\left(\bar{\Omega}_{2} \backslash \Omega_{1}\right) \rightarrow K$ is a completely continuous operator such that either

(i) $\|A u\| \leq\|u\|$ for $u \in K \cap \partial \Omega_{1}$ and $\|A u\| \geq\|u\|$ for $u \in K \cap \partial \Omega_{2}$; or

(ii) $\|A u\| \geq\|u\|$ for $u \in K \cap \partial \Omega_{1}$ and $\|A u\| \leq\|u\|$ for $u \in K \cap \partial \Omega_{2}$.

Then $A$ has a fixed point in $K \cap\left(\bar{\Omega}_{2} \backslash \Omega_{1}\right)$.

\section{Preliminary lemmas}

In this section, we adopt the ideas and the method which have been widely used and which are due to Webb and Infante in $[1,2]$.

In our case, the existence of positive solutions of nonlocal BVP

$$
\left\{\begin{array}{l}
u^{\prime \prime \prime}(t)+f\left(t, u(t), u^{\prime}(t)\right)=0, \quad 0<t<1 \\
u(0)=0 \\
a u^{\prime}(0)-b u^{\prime \prime}(0)=\alpha[u] \\
c u^{\prime}(1)+d u^{\prime \prime}(1)=\beta[u]
\end{array}\right.
$$

with two nonlocal boundary terms $\alpha[u], \beta[u]$ can be studied via a perturbed Hammerstein integral equation of the type

$$
u(t)=\gamma(t) \alpha[u]+\delta(t) \beta[u]+\int_{0}^{1} G(t, s) f\left(s, u(s), u^{\prime}(s)\right) d s=: T_{1} u(t) .
$$

Here $\gamma(t), \delta(t)$ are linearly independent and given by

$$
\begin{array}{ll}
-\gamma^{\prime \prime \prime}(t)=0, & \gamma(0)=0, \quad a \gamma^{\prime}(0)-b \gamma^{\prime \prime}(0)=1, \quad c \gamma^{\prime}(1)+d \gamma^{\prime \prime}(1)=0, \\
-\delta^{\prime \prime \prime}(t)=0, & \delta(0)=0, \quad a \delta^{\prime}(0)-b \delta^{\prime \prime}(0)=0, \quad c \delta^{\prime}(1)+d \delta^{\prime \prime}(1)=1,
\end{array}
$$


which imply $\gamma(t)=\frac{2 c t+2 d t-c t^{2}}{2 \rho}$ and $\delta(t)=\frac{a t^{2}+2 b t}{2 \rho}, t \in[0,1]$. Let $\|\cdot\|_{\infty}$ be the usual supremum norm in $C[0,1]$. A direct calculation shows that for $t \in[\theta, 1-\theta], 0<\theta<\frac{1}{2}$,

$$
\begin{aligned}
& \gamma(t) \geq c_{1}\|\gamma\|_{\infty}, \quad \delta(t) \geq c_{2}\|\delta\|_{\infty}, \\
& \gamma^{\prime}(t) \geq d_{1}\left\|\gamma^{\prime}\right\|_{\infty} \quad \text { and } \quad \delta^{\prime}(t) \geq d_{2}\left\|\delta^{\prime}\right\|_{\infty},
\end{aligned}
$$

where $c_{1}=\frac{2 c \theta+2 d \theta-c \theta^{2}}{c+2 d}, c_{2}=\frac{a \theta^{2}+2 b \theta}{a+2 b}, d_{1}=\frac{c \theta+d}{c+d}$ and $d_{2}=\frac{a \theta+b}{a+b} ; G(t, s)$ is Green's function for the corresponding problem with local terms when $\alpha[u]$ and $\beta[u]$ are identically 0 , i.e.,

$$
G(t, s)= \begin{cases}\frac{\left(a t^{2}+2 b t\right)(c(1-s)+d)}{2 \rho}-\frac{(t-s)^{2}}{2}, & 0 \leq s \leq t \leq 1, \\ \frac{\left(a t^{2}+2 b t\right)(c(1-s)+d)}{2 \rho}, & 0 \leq t \leq s \leq 1 .\end{cases}
$$

In the remainder of this paper, we always assume that

(H1) $0 \leq \alpha[\gamma], \beta[\delta]<1, \alpha[\delta], \beta[\gamma] \geq 0$ and $D:=(1-\alpha[\gamma])(1-\beta[\delta])-\alpha[\delta] \beta[\gamma]>0$;

(H2) $A, B$ are functions of bounded variation, and $\mathcal{K}_{A}(s), \mathcal{K}_{B}(s) \geq 0$ for $s \in[0,1]$, where

$$
\mathcal{K}_{A}(s):=\int_{0}^{1} G(t, s) d A(t) \text { and } \mathcal{K}_{B}(s):=\int_{0}^{1} G(t, s) d B(t) .
$$

As shown in Theorem 2.3 in [1], if $u$ is a fixed point of $T_{1}$ in (2.2), then $u$ is a fixed point of $S$, which is now given by

$$
\begin{aligned}
\operatorname{Su}(t):= & \frac{\gamma(t)}{D}\left((1-\beta[\delta]) \int_{0}^{1} \mathcal{K}_{A}(s) f\left(s, u(s), u^{\prime}(s)\right) d s+\alpha[\delta] \int_{0}^{1} \mathcal{K}_{B}(s) f\left(s, u(s), u^{\prime}(s)\right) d s\right) \\
& +\frac{\delta(t)}{D}\left(\beta[\gamma] \int_{0}^{1} \mathcal{K}_{A}(s) f\left(s, u(s), u^{\prime}(s)\right) d s\right. \\
& \left.+(1-\alpha[\gamma]) \int_{0}^{1} \mathcal{K}_{B}(s) f\left(s, u(s), u^{\prime}(s)\right) d s\right)+\int_{0}^{1} G(t, s) f\left(s, u(s), u^{\prime}(s)\right) d s \\
= & : \int_{0}^{1} G_{S}(t, s) f\left(s, u(s), u^{\prime}(s)\right) d s
\end{aligned}
$$

in our case. The kernel $G_{S}$ is Green's function corresponding to BVP (2.1). By Lemma 2.1 and Lemma 2.2 in [14], we can get the following properties of Green's function.

Lemma 2.1 Let $\rho:=a c+a d+b c>0, c_{3}=\frac{\rho \int_{0}^{\theta} \Phi(\tau) d \tau}{(a+b)(c+d)}, 0<\theta<1$. Then $G(t, s)$ satisfies

$$
\begin{aligned}
& G(t, s) \leq \Phi(s) \quad \text { for } t \in[0,1], s \in[0,1] \\
& G(t, s) \geq c_{3} \Phi(s) \quad \text { for } t \in[\theta, 1-\theta], s \in[0,1]
\end{aligned}
$$

where $\Phi(s)=\frac{1}{\rho}(b+a s)(d+c(1-s)), s \in[0,1]$.

Lemma 2.2 Let $c_{0}=\min \left\{c_{1}, c_{2}, c_{3}\right\}$. Then $G_{S}(t, s)$ satisfies

$$
\begin{aligned}
& G_{S}(t, s) \leq \Phi_{1}(s) \quad \text { for } t \in[0,1], s \in[0,1], \\
& G_{S}(t, s) \geq c_{0} \Phi_{1}(s) \quad \text { for } t \in[\theta, 1-\theta], s \in[0,1],
\end{aligned}
$$


where $\Phi_{1}(s):=\frac{\|\gamma\|_{\infty}}{D}\left((1-\beta[\delta]) \mathcal{K}_{A}(s)+\alpha[\delta] \mathcal{K}_{B}(s)\right)+\frac{\|\delta\|_{\infty}}{D}\left(\beta[\gamma] \mathcal{K}_{A}(s)+(1-\alpha[\gamma]) \mathcal{K}_{B}(s)\right)+\Phi(s)$, $s \in[0,1]$.

Lemma 2.3 Let $d_{0}=\min \left\{d_{1}, d_{2}, d_{3}\right\}, d_{3}=\frac{\rho \min _{t \in[\theta, 1-\theta]} \Phi(t)}{(a+b)(c+d)}, 0<\theta<1$, and

$$
\begin{aligned}
\Phi_{2}(s):= & \frac{\left\|\gamma^{\prime}\right\|_{\infty}}{D}\left[(1-\beta[\delta]) \mathcal{K}_{A}(s)+\alpha[\delta] \mathcal{K}_{B}(s)\right] \\
& +\frac{\left\|\delta^{\prime}\right\|_{\infty}}{D}\left[\beta[\gamma] \mathcal{K}_{A}(s)+(1-\alpha[\gamma]) \mathcal{K}_{B}(s)\right]+\Phi(s) .
\end{aligned}
$$

Then $\frac{\partial G_{S}(t, s)}{\partial t}$ satisfies

$$
\begin{aligned}
& \frac{\partial G_{S}(t, s)}{\partial t} \leq \Phi_{2}(s) \quad \text { for } t \in[0,1], s \in[0,1] \\
& \frac{\partial G_{S}(t, s)}{\partial t} \geq d_{0} \Phi_{2}(s) \quad \text { for } t \in[\theta, 1-\theta], s \in[0,1] .
\end{aligned}
$$

Proof For $s \in[0,1]$, by the fact

$$
\frac{\frac{\partial G(t, s)}{\partial t}}{\Phi(s)}= \begin{cases}\frac{(b+a s)(d+c(1-t))}{(b+a s)(d+c(1-s))}=\frac{(b+a t)(d+c(1-t))}{(b+a t)(d+c(1-s))} \geq \frac{\rho \Phi(t)}{(a+b)(c+d)}, & 0 \leq s \leq t \leq 1, \\ \frac{(b+a t)(d+c(1-s))}{(b+a s)(d+c(1-s))}=\frac{(b+a t)(d+c(1-t))}{(b+a s)(d+c(1-t))} \geq \frac{\rho \Phi(t)}{(a+b)(c+d)}, & 0 \leq t \leq s \leq 1,\end{cases}
$$

so $\frac{\partial G(t, s)}{\partial t} \geq \frac{\rho \min _{t \in[\theta, 1-\theta]} \Phi(t)}{(a+b)(c+d)} \Phi(s), t \in[\theta, 1-\theta], s \in[0,1]$, which together with (2.3) shows that $\frac{\partial G_{S}(t, s)}{\partial t} \geq d_{0} \Phi_{2}(s)$ holds.

Let $E=\left\{C^{1}[0,1]: u(0)=0\right\}$ equipped with the norm $\|u\|=\max \left\{\|u\|_{\infty},\left\|u^{\prime}\right\|_{\infty}\right\}$, where $\|u\|_{\infty}$ is the usual supremum norm in $C[0,1]$. Similar to Lemma 2.1 in [29], we can get the following lemma.

Lemma 2.4 If $u \in E$, then $\|u\|_{\infty} \leq\left\|u^{\prime}\right\|_{\infty}$. And so, $E$ is a Banach space when it is endowed with the norm $\|u\|=\left\|u^{\prime}\right\|_{\infty}$.

Define

$$
K=\left\{u \in E: u(t) \geq 0, u^{\prime}(t) \geq 0, t \in[0,1], \min _{t \in[\theta, 1-\theta]} u^{\prime}(t) \geq d_{0}\|u\|\right\} .
$$

Then it is easy to verify that $K$ is a cone in $E$.

For $u \in K$, we define

$$
\begin{aligned}
(T u)(t)= & \int_{0}^{1} G_{S}(t, s) f\left(s, \int_{0}^{1} G_{S}(s, \tau) g\left(\tau, u(\tau), u^{\prime}(\tau)\right) d \tau,\right. \\
& \left.\int_{0}^{1} \frac{\partial G_{S}(s, \tau)}{\partial s} g\left(\tau, u(\tau), u^{\prime}(\tau)\right) d \tau\right) d s, \quad t \in[0,1] .
\end{aligned}
$$

It is easy to see that if $x$ is a fixed point of $T$ in $K$, then BVP (1.6) has one solution $(u, v)$, where

$$
\left\{\begin{array}{l}
u(t)=x(t), \\
v(t)=\int_{0}^{1} G_{S}(t, s) g\left(s, x(s), x^{\prime}(s)\right) d s .
\end{array}\right.
$$


Lemma 2.5 $T: K \rightarrow K$.

Proof It is obvious that $(T u)(t) \geq 0$ and $(T u)^{\prime}(t) \geq 0$. Moreover, for $t \in[0,1]$, by Lemma 2.3, we have

$$
\begin{aligned}
(T u)^{\prime}(t)= & \int_{0}^{1} \frac{\partial G_{S}(t, s)}{\partial t} f\left(s, \int_{0}^{1} G_{S}(s, \tau) g\left(\tau, u(\tau), u^{\prime}(\tau)\right) d \tau\right. \\
& \left.\int_{0}^{1} \frac{\partial G_{S}(s, \tau)}{\partial s} g\left(\tau, u(\tau), u^{\prime}(\tau)\right) d \tau\right) d s \\
\leq & \int_{0}^{1} \Phi_{2}(s) f\left(s, \int_{0}^{1} G_{S}(s, \tau) g\left(\tau, u(\tau), u^{\prime}(\tau)\right) d \tau\right. \\
& \left.\int_{0}^{1} \frac{\partial G_{S}(s, \tau)}{\partial s} g\left(\tau, u(\tau), u^{\prime}(\tau)\right) d \tau\right) d s
\end{aligned}
$$

and hence

$$
\begin{aligned}
\|T u\| \leq & \int_{0}^{1} \Phi_{2}(s) f\left(s, \int_{0}^{1} G_{S}(s, \tau) g\left(\tau, u(\tau), u^{\prime}(\tau)\right) d \tau,\right. \\
& \left.\int_{0}^{1} \frac{\partial G_{S}(s, \tau)}{\partial s} g\left(\tau, u(\tau), u^{\prime}(\tau)\right) d \tau\right) d s .
\end{aligned}
$$

Moreover, it follows from Lemma 2.2 that for $t \in[\theta, 1-\theta]$,

$$
\begin{aligned}
(T u)^{\prime}(t)= & \int_{0}^{1} \frac{\partial G_{S}(t, s)}{\partial t} f\left(s, \int_{0}^{1} G_{S}(s, \tau) g\left(\tau, u(\tau), u^{\prime}(\tau)\right) d \tau,\right. \\
& \left.\int_{0}^{1} \frac{\partial G_{S}(s, \tau)}{\partial s} g\left(\tau, u(\tau), u^{\prime}(\tau)\right) d \tau\right) d s \\
\geq & d_{0} \int_{0}^{1} \Phi_{2}(s) f\left(s, \int_{0}^{1} G_{S}(s, \tau) g\left(\tau, u(\tau), u^{\prime}(\tau)\right) d \tau\right. \\
& \left.\int_{0}^{1} \frac{\partial G_{S}(s, \tau)}{\partial s} g\left(\tau, u(\tau), u^{\prime}(\tau)\right) d \tau\right) d s \\
\geq & d_{0}\|T u\| .
\end{aligned}
$$

Then we get

$$
\min _{t \in[\theta, 1-\theta]}(T u)^{\prime}(t) \geq d_{0}\|T u\|,
$$

which shows that $T K \subset K$.

Similar to the proof of Lemma 2.4 in [28], we can get the following lemma.

Lemma 2.6 $T: K \rightarrow K$ is completely continuous.

\section{Main results}

Denote

$$
f^{0}=\limsup _{x+y \rightarrow 0^{+}} \max _{t \in[0,1]} \frac{f(t, x, y)}{x+y} \quad \text { and } \quad g^{0}=\limsup _{x+y \rightarrow 0^{+}} \max _{t \in[0,1]} \frac{g(t, x, y)}{x+y},
$$




$$
\begin{aligned}
& f_{0}=\liminf _{x+y \rightarrow 0^{+}} \min _{t \in[\theta, 1-\theta]} \frac{f(t, x, y)}{x+y} \text { and } g_{0}=\liminf _{x+y \rightarrow 0^{+}} \min _{t \in[\theta, 1-\theta]} \frac{g(t, x, y)}{x+y}, \\
& f^{\infty}=\limsup _{x+y \rightarrow+\infty} \max _{t \in[0,1]} \frac{f(t, x, y)}{x+y} \text { and } g^{\infty}=\limsup _{x+y \rightarrow+\infty} \max _{t \in[0,1]} \frac{g(t, x, y)}{x+y} \\
& f_{\infty}=\liminf _{x+y \rightarrow+\infty} \min _{t \in[\theta, 1-\theta]} \frac{f(t, x, y)}{x+y} \text { and } g_{\infty}=\liminf _{x+y \rightarrow+\infty} \min _{t \in[\theta, 1-\theta]} \frac{g(t, x, y)}{x+y} \\
& A_{1}=\int_{0}^{1} \Phi_{2}(s) d s, \quad B_{1}=2 \int_{0}^{1}\left(\Phi_{1}(s)+\Phi_{2}(s)\right) d s \\
& A_{2}=d_{0} \int_{\theta}^{1-\theta} \Phi_{2}(s) d s, \quad B_{2}=d_{0} \int_{\theta}^{1-\theta}\left(c_{0} \Phi_{1}(s)+d_{0} \Phi_{2}(s)\right) d s .
\end{aligned}
$$

Theorem 3.1 Assume that $A_{1} f^{0}<1<A_{2} f_{\infty}$ and $B_{1} g^{0}<1<B_{2} g_{\infty}$. Then BVP (1.6) has at least one positive solution.

Proof In view of $A_{1} f^{0}<1$ and $B_{1} g^{0}<1$, there exists $\varepsilon_{1}>0$ such that

$$
A_{1}\left(f^{0}+\varepsilon_{1}\right) \leq 1, \quad B_{1}\left(g^{0}+\varepsilon_{1}\right) \leq 1 .
$$

By the definition of $f^{0}, g^{0}$, we may choose $\sigma_{1}>0$ so that

$$
\begin{aligned}
& f(t, x, y) \leq\left(f^{0}+\varepsilon_{1}\right)(x+y), \\
& g(t, x, y) \leq\left(g^{0}+\varepsilon_{1}\right)(x+y), \quad t \in[0,1],(x+y) \in\left[0, \sigma_{1}\right] .
\end{aligned}
$$

Set $\Omega_{1}=\left\{u \in E \mid\|u\|<\sigma_{1} / 2\right\}$. It follows from (3.1), (3.2), Lemmas 2.2 and 2.3 that for any $u \in K \cap \partial \Omega_{1}, s \in[0,1]$,

$$
\begin{aligned}
& \int_{0}^{1}\left(G_{S}(s, \tau)+\frac{\partial G_{S}(s, \tau)}{\partial s}\right) g\left(\tau, u(\tau), u^{\prime}(\tau)\right) d \tau \\
& \quad \leq \int_{0}^{1}\left(\Phi_{1}(\tau)+\Phi_{2}(\tau)\right)\left(g^{0}+\varepsilon_{1}\right)\left(u(\tau)+u^{\prime}(\tau)\right) d \tau \\
& \quad \leq 2\|u\|\left(g^{0}+\varepsilon_{1}\right) \int_{0}^{1}\left(\Phi_{1}(\tau)+\Phi_{2}(\tau)\right) d \tau \\
& \quad \leq \sigma_{1} .
\end{aligned}
$$

Then, by (3.1), (3.2) and (3.3), we have

$$
\begin{aligned}
(T u)^{\prime}(t)= & \int_{0}^{1} \frac{\partial G_{S}(t, s)}{\partial t} f\left(s, \int_{0}^{1} G_{S}(s, \tau) g\left(\tau, u(\tau), u^{\prime}(\tau)\right) d \tau\right. \\
& \left.\int_{0}^{1} \frac{\partial G_{S}(s, \tau)}{\partial s} g\left(\tau, u(\tau), u^{\prime}(\tau)\right) d \tau\right) d s \\
\leq & \int_{0}^{1} \Phi_{2}(s)\left(f^{0}+\varepsilon_{1}\right)\left(\int_{0}^{1} G_{S}(s, \tau) g\left(\tau, u(\tau), u^{\prime}(\tau)\right) d \tau\right. \\
& \left.+\int_{0}^{1} \frac{\partial G_{S}(s, \tau)}{\partial s} g\left(\tau, u(\tau), u^{\prime}(\tau)\right) d \tau\right) d s \\
\leq & \int_{0}^{1} \Phi_{2}(s)\left(f^{0}+\varepsilon_{1}\right)\left(\int_{0}^{1}\left(\Phi_{1}(\tau)+\Phi_{2}(\tau)\right)\left(g^{0}+\varepsilon_{1}\right)\left(u(\tau)+u^{\prime}(\tau)\right) d \tau\right) d s
\end{aligned}
$$




$$
\begin{aligned}
& \leq \int_{0}^{1} \Phi_{2}(s) d s\left(f^{0}+\varepsilon_{1}\right)\left(\int_{0}^{1}\left(\Phi_{1}(s)+\Phi_{2}(s)\right) d s\right)\left(g^{0}+\varepsilon_{1}\right) 2\|u\| \\
& \leq\|u\|, \quad t \in[0,1] .
\end{aligned}
$$

Therefore,

$$
\|T u\| \leq\|u\|, \quad u \in K \cap \partial \Omega_{1} .
$$

On the other hand, since $1<A_{2} f_{\infty}$ and $1<B_{2} g_{\infty}$, there exists $\varepsilon_{2}>0$ such that

$$
A_{2}\left(f_{\infty}-\varepsilon_{2}\right) \geq 1, \quad B_{2}\left(g_{\infty}-\varepsilon_{2}\right) \geq 1 .
$$

By the definition of $f_{\infty}, g_{\infty}$, we may choose $\sigma_{2}^{\prime}>\sigma_{1}$ so that

$$
\begin{aligned}
& f(t, x, y) \geq\left(f_{\infty}-\varepsilon_{2}\right)(x+y), \\
& g(t, x, y) \geq\left(g_{\infty}-\varepsilon_{2}\right)(x+y), \quad t \in[\theta, 1-\theta],(x+y) \in\left[\sigma_{2}^{\prime},+\infty\right) .
\end{aligned}
$$

Let $\sigma_{2}=\max \left\{2 \sigma_{1}, \sigma_{2}^{\prime} / d_{0}\right\}$ and set $\Omega_{2}=\left\{u \in E \mid\|u\|<\sigma_{2}\right\}$. Then $u \in K \cap \partial \Omega_{2}$ implies that $\sigma_{2}^{\prime} \leq d_{0}\|u\| \leq u^{\prime}(t), t \in[\theta, 1-\theta]$. So, for $s \in[\theta, 1-\theta]$, in view of Lemmas 2.2 and 2.3, we have

$$
\begin{aligned}
& \int_{0}^{1}\left(G_{S}(s, \tau)+\frac{\partial G_{S}(s, \tau)}{\partial s}\right) g\left(\tau, u(\tau), u^{\prime}(\tau)\right) d \tau \\
& \quad \geq \int_{\theta}^{1-\theta}\left(c_{0} \Phi_{1}(\tau)+d_{0} \Phi_{2}(\tau)\right)\left(g_{\infty}-\varepsilon_{2}\right)\left(u(\tau)+u^{\prime}(\tau)\right) d \tau \\
& \quad \geq\|u\|\left(g_{\infty}-\varepsilon_{2}\right) d_{0} \int_{\theta}^{1-\theta}\left(c_{0} \Phi_{1}(\tau)+d_{0} \Phi_{2}(\tau)\right) d \tau \geq \sigma_{2} .
\end{aligned}
$$

Then, for $t \in[\theta, 1-\theta]$, by (3.5), (3.6), (3.7), Lemmas 2.2 and 2.3, we have

$$
\begin{aligned}
(T u)^{\prime}(t)= & \int_{0}^{1} \frac{\partial G_{S}(t, s)}{\partial t} f\left(s, \int_{0}^{1} G_{S}(s, \tau) g\left(\tau, u(\tau), u^{\prime}(\tau)\right) d \tau\right. \\
& \left.\int_{0}^{1} \frac{\partial G_{S}(s, \tau)}{\partial s} g\left(\tau, u(\tau), u^{\prime}(\tau)\right) d \tau\right) d s \\
\geq & d_{0} \int_{\theta}^{1-\theta} \Phi_{2}(s)\left(f_{\infty}-\varepsilon_{2}\right)\left(\int_{0}^{1}\left(G_{S}(s, \tau)+\frac{\partial G_{S}(s, \tau)}{\partial s}\right) g\left(\tau, u(\tau), u^{\prime}(\tau)\right) d \tau\right) d s \\
\geq & d_{0} \int_{\theta}^{1-\theta} \Phi_{2}(s) d s\left(f_{\infty}-\varepsilon_{2}\right) \sigma_{2} \\
\geq & \|u\|, \quad t \in[0,1] .
\end{aligned}
$$

Therefore,

$$
\|T u\| \geq\|u\|, \quad u \in K \cap \partial \Omega_{2}
$$

Therefore, it follows from the first part of Theorem 1.1 that $T$ has a fixed point $u_{1} \in K \cap$ $\left(\bar{\Omega}_{2} \backslash \Omega_{1}\right)$. Consequently, BVP (1.6) has a positive solution $(u, v) \in K \times K$, here

$$
\left\{\begin{array}{l}
u(t)=u_{1}(t), \\
v(t)=\int_{0}^{1} G_{S}(t, s) g\left(s, u_{1}(s), u_{1}^{\prime}(s)\right) d s .
\end{array}\right.
$$


Theorem 3.2 Assume that $A_{1} f^{\infty}<1<A_{2} f_{0}$ and $B_{1} g^{\infty}<1<B_{2} g_{0}$. Then BVP (1.6) has at least one positive solution.

Proof The proof is similar to Theorem 3.1 and therefore omitted.

Theorem 3.3 Assume that $A_{2} f_{0}>1, A_{2} f_{\infty}>1, B_{2} g_{0}>1, B_{2} g_{\infty}>1, B_{2} g^{0}<2$ and there is a $\mu>0$ such that

$$
\begin{aligned}
& \max \{g(t, x, y), t \in[0,1],(x+y) \in[0, \mu]\}<\frac{2 \mu}{B_{1}} \\
& \max \{f(t, x, y), t \in[0,1],(x+y) \in[0, \mu]\}<\frac{\mu}{2 A_{1}}
\end{aligned}
$$

Then BVP (1.6) has at least two positive solutions.

Proof Firstly, in view of $A_{2} f_{0}>1$ and $B_{2} g_{0}>1$, there exists $\varepsilon>0$ such that

$$
A_{2}\left(f_{0}-\varepsilon\right) \geq 1, \quad B_{2}\left(g_{0}-\varepsilon\right) \geq 1 .
$$

By the definition of $f_{0}, g_{0}$, we may choose $\hat{\sigma}_{1}>0$ so that

$$
\begin{aligned}
& f(t, x, y) \geq\left(f_{0}-\varepsilon\right)(x+y), \\
& g(t, x, y) \geq\left(g_{0}-\varepsilon\right)(x+y), \quad t \in[0,1],(x+y) \in\left[0, \hat{\sigma}_{1}\right] .
\end{aligned}
$$

Moreover, from $B_{2} g^{0}<2$, take $\rho_{1}$ satisfying $0<\rho_{1}<\frac{B_{2}}{B_{1}} \hat{\sigma}_{1}<\mu$ such that

$$
g(t, x, y) \leq \frac{2 \rho_{1}}{B_{2}}, \quad \forall t \in[0,1], x+y \in\left[0, \rho_{1}\right]
$$

Set $\Omega_{1}=\left\{u \in E \mid\|u\|<\rho_{1} / 2\right\}$. It follows from (3.11), (3.12), Lemmas 2.2 and 2.3 that for any $u \in K \cap \partial \Omega_{1}$,

$$
\begin{aligned}
\int_{0}^{1}\left(G_{S}(s, \tau)+\frac{\partial G_{S}(s, \tau)}{\partial s}\right) g\left(\tau, u(\tau), u^{\prime}(\tau)\right) d \tau & \leq \frac{2 \rho_{1}}{B_{2}} \int_{0}^{1}\left(\Phi_{1}(\tau)+\Phi_{2}(\tau)\right) d \tau \\
& =\frac{B_{1}}{B_{2}} \rho_{1}<\hat{\sigma}_{1}, \quad s \in[0,1] .
\end{aligned}
$$

Then, for $t \in[\theta, 1-\theta]$, by (3.11), (3.12), (3.13), Lemmas 2.2 and 2.3, we have

$$
\begin{aligned}
(T u)^{\prime}(t)= & \int_{0}^{1} \frac{\partial G_{S}(t, s)}{\partial t} f\left(s, \int_{0}^{1} G_{S}(s, \tau) g\left(\tau, u(\tau), u^{\prime}(\tau)\right) d \tau\right. \\
& \left.\int_{0}^{1} \frac{\partial G_{S}(s, \tau)}{\partial s} g\left(\tau, u(\tau), u^{\prime}(\tau)\right) d \tau\right) d s \\
\geq & d_{0} \int_{\theta}^{1-\theta} \Phi_{2}(s)\left(f_{0}-\varepsilon\right)\left(\int_{0}^{1}\left(G_{S}(s, \tau)+\frac{\partial G_{S}(s, \tau)}{\partial s}\right) g\left(\tau, u(\tau), u^{\prime}(\tau)\right) d \tau\right) d s \\
\geq & d_{0} \int_{\theta}^{1-\theta} \Phi_{2}(s)\left(f_{0}-\varepsilon\right)\left(\int_{\theta}^{1-\theta}\left(G_{S}(s, \tau)+\frac{\partial G_{S}(s, \tau)}{\partial s}\right) g\left(\tau, u(\tau), u^{\prime}(\tau)\right) d \tau\right) d s
\end{aligned}
$$




$$
\begin{aligned}
\geq & d_{0} \int_{\theta}^{1-\theta} \Phi_{2}(s)\left(f_{0}-\varepsilon\right) \\
& \times\left(\int_{\theta}^{1-\theta}\left(c_{0} \Phi_{1}(\tau)+d_{0} \Phi_{2}(\tau)\right)\left(g_{0}-\varepsilon\right)\left(u(\tau)+u^{\prime}(\tau)\right) d \tau\right) d s \\
\geq & d_{0} \int_{\theta}^{1-\theta} \Phi_{2}(s) d s\left(f_{0}-\varepsilon\right)\left(\int_{\theta}^{1-\theta}\left(c_{0} \Phi_{1}(\tau)+d_{0} \Phi_{2}(\tau)\right) d \tau\right)\left(g_{0}-\varepsilon\right) d_{0}\|u\| \\
\geq & \|u\|, \quad t \in[0,1] .
\end{aligned}
$$

Thus,

$$
\|T u\| \geq\|u\|, \quad u \in K \cap \partial \Omega_{1}
$$

Secondly, similar to the proof of (3.8), we may choose $\sigma_{2}>\mu$ and set $\Omega_{2}=\{u \in E \mid\|u\|<$ $\left.\sigma_{2}\right\}$, and easily get

$$
\|T u\| \geq\|u\|, \quad u \in K \cap \partial \Omega_{2}
$$

Let $\Omega_{3}=\{u \in E \mid\|u\|<\mu / 2\}$. Then, for any $u \in K \cap \partial \Omega_{3}$, it follows by (3.9) and (3.10) that

$$
\begin{aligned}
\int_{0}^{1}\left(G_{S}(s, \tau)+\frac{\partial G_{S}(s, \tau)}{\partial s}\right) g\left(\tau, u(\tau), u^{\prime}(\tau)\right) d \tau & \leq \frac{2 \mu}{B_{1}} \int_{0}^{1}\left(\Phi_{1}(\tau)+\Phi_{2}(\tau)\right) d \tau \\
& \leq \mu, \quad s \in[0,1]
\end{aligned}
$$

and

$$
\begin{aligned}
(T u)^{\prime}(t)= & \int_{0}^{1} \frac{\partial G_{S}(t, s)}{\partial t} f\left(s, \int_{0}^{1} G_{S}(s, \tau) g\left(\tau, u(\tau), u^{\prime}(\tau)\right) d \tau,\right. \\
& \left.\int_{0}^{1} \frac{\partial G_{S}(s, \tau)}{\partial s} g\left(\tau, u(\tau), u^{\prime}(\tau)\right) d \tau\right) d s \\
< & \int_{0}^{1} \Phi_{2}(s) d s \frac{\mu}{2 A_{1}}=\frac{\mu}{2}=\|u\|, \quad t \in[0,1] .
\end{aligned}
$$

Thus,

$$
\|T u\|<\|u\|, \quad u \in K \cap \partial \Omega_{3},
$$

which together with (3.13), (3.14) shows that $T$ has at least two fixed points in $u_{1} \in K \cap$ $\left(\bar{\Omega}_{2} \backslash \Omega_{3}\right)$ and $u_{2} \in K \cap\left(\bar{\Omega}_{3} \backslash \Omega_{1}\right)$.

Similarly, we can get the following theorem.

Theorem 3.4 Assume that $A_{1} f^{0}<1, A_{1} f^{\infty}<\frac{1}{2}, B_{1} g^{0}<1, B_{2} g_{\infty}>d_{0}$ and there exists $\eta>0$ such that

$$
\begin{aligned}
& \max \left\{g(t, x, y), t \in[\theta, 1-\theta],(x+y) \in\left[d_{0} \eta,+\infty\right)\right\}>\frac{d_{0}^{2} \eta}{B_{2}} \\
& \max \left\{f(t, x, y), t \in[\theta, 1-\theta],(x+y) \in\left[d_{0} \eta,+\infty\right)\right\}>\frac{\eta}{A_{2}}
\end{aligned}
$$

Then BVP (1.6) has at least two positive solutions. 
Theorem 3.5 If $A_{1} f(t, x, y)<(x+y)$ and $B_{1} g(t, x, y)<(x+y)$ for $t \in[0,1]$ and $(x+y) \in$ $[0,+\infty)$, then $B V P(1.6)$ has no monotone positive solution.

Proof Suppose on the contrary that $u$ is a monotone positive solution of BVP (1.6). Then $u(t) \geq 0$ and $u^{\prime}(t) \geq 0$ for $t \in[0,1]$, and

$$
\begin{aligned}
u^{\prime}(t)= & \int_{0}^{1} \frac{\partial G_{S}(t, s)}{\partial t} f\left(s, \int_{0}^{1} G_{S}(s, \tau) g\left(\tau, u(\tau), u^{\prime}(\tau)\right) d \tau,\right. \\
& \left.\int_{0}^{1} \frac{\partial G_{S}(s, \tau)}{\partial s} g\left(\tau, u(\tau), u^{\prime}(\tau)\right) d \tau\right) d s \\
< & \frac{1}{A_{1}} \int_{0}^{1} \Phi_{2}(s)\left(\int_{0}^{1} G_{S}(s, \tau) g\left(\tau, u(\tau), u^{\prime}(\tau)\right) d \tau\right. \\
& \left.+\int_{0}^{1} \frac{\partial G_{S}(s, \tau)}{\partial s} g\left(\tau, u(\tau), u^{\prime}(\tau)\right) d \tau\right) d s \\
< & \frac{1}{A_{1}} \frac{1}{B_{1}} \int_{0}^{1} \Phi_{2}(s) d s \int_{0}^{1}\left(\Phi_{1}(s)+\Phi_{2}(s)\right) d s \int_{0}^{1}\left(u(\tau)+u^{\prime}(\tau)\right) d \tau \\
< & \|u\|,
\end{aligned}
$$

which shows that $\|u\|<\|u\|$. This is a contradiction.

Similarly, we can prove the following theorem.

Theorem 3.6 If $A_{2} f(t, x, y)>(x+y)$ and $B_{2} g(t, x, y)>(x+y)$ for $t \in[\theta, 1-\theta]$ and $(x+y) \in$ $[0,+\infty)$, then $B V P(1.6)$ has no monotone positive solution.

\section{Example}

In this section, we give an example to illustrate our main results.

Consider the BVP:

$$
\left\{\begin{array}{l}
-u^{\prime \prime \prime}(t)=f\left(t, v(t), v^{\prime}(t)\right), \quad t \in(0,1), \\
-v^{\prime \prime \prime}(t)=g\left(t, u(t), u^{\prime}(t)\right), \quad t \in(0,1), \\
u(0)=0, \quad u^{\prime}(0)=\alpha[u]=\int_{0}^{1}(1-s) u(s) d s, \quad u^{\prime}(1)=\beta[u]=\int_{0}^{1} s u(s) d s, \\
v(0)=0, \quad v^{\prime}(0)=\alpha[v]=\int_{0}^{1}(1-s) v(s) d s, \quad v^{\prime}(1)=\beta[v]=\int_{0}^{1} s v(s) d s .
\end{array}\right.
$$

For this BCs, the corresponding $\gamma(t)=\frac{2 t-t^{2}}{2}$ and $\delta(t)=\frac{t^{2}}{2}$. A simple calculation shows that

$$
\begin{aligned}
& \alpha[\gamma]=\frac{1}{8}, \quad \alpha[\delta]=\frac{1}{24}, \quad \beta[\gamma]=\frac{5}{24}, \quad \beta[\delta]=\frac{1}{8}, \\
& D=(1-\alpha[\gamma])(1-\beta[\delta])-\alpha[\delta] \beta[\gamma]=\frac{109}{144}, \\
& \mathcal{K}_{A}(s):=\int_{0}^{1} G(t, s)(1-t) d t=\frac{s}{8}-\frac{s^{2}}{4}+\frac{s^{3}}{6}-\frac{s^{4}}{24}, \\
& \mathcal{K}_{B}(s):=\int_{0}^{1} G(t, s) t d t=\frac{5 s}{24}-\frac{s^{2}}{4}+\frac{s^{4}}{24}, \\
& \Phi_{1}(s)=\frac{265 s}{218}-\frac{145 s^{2}}{109}+\frac{13 s^{3}}{109}-\frac{s^{4}}{218}, \quad \Phi_{2}(s)=\frac{156 s}{109}-\frac{181 s^{2}}{109}+\frac{26 s^{3}}{109}-\frac{s^{4}}{109} .
\end{aligned}
$$


Let $\theta=1 / 4$, then $A_{1}=719 / 3,270 \approx 0.2199, A_{2}=126,517 / 3,348,480 \approx 0.0378, B_{1}=$ $2,767 / 3,270 \approx 0.8462, B_{2}=4,438,339 / 428,605,440 \approx 0.0104$.

\section{Example 4.1 Let}

$$
\begin{aligned}
& f\left(t, v(t), v^{\prime}(t)\right)=\frac{1}{1+t}\left[\frac{v(t)+v^{\prime}(t)}{e^{v(t)+v^{\prime}(t)}}+\frac{1,000\left(v(t)+v^{\prime}(t)\right)^{2}}{1+v(t)+v^{\prime}(t)}\right], \\
& g\left(t, u(t), u^{\prime}(t)\right)=\frac{1}{10(1+t)}\left[\frac{u(t)+u^{\prime}(t)}{e^{u(t)+u^{\prime}(t)}}+\frac{2,000\left(u(t)+u^{\prime}(t)\right)^{2}}{1+u(t)+u^{\prime}(t)}\right] .
\end{aligned}
$$

It is easy to compute that $f^{0}=1, f_{\infty}=\frac{4,000}{7}, g^{0}=\frac{1}{10}, g_{\infty}=\frac{800}{7}$, which show that $A_{1} f^{0}<1<$ $A_{2} f_{\infty}$ and $B_{1} g^{0}<1<B_{2} g_{\infty}$. So, it follows from Theorem 3.1 that BVP (4.1) has at least one positive solution.

Example 4.2 Let

$$
\begin{aligned}
& f\left(t, v(t), v^{\prime}(t)\right)=\frac{1}{1+t}\left[\frac{50\left(v(t)+v^{\prime}(t)\right)}{\left.e^{v(t)+v^{\prime}(t)}+\frac{50\left(v(t)+v^{\prime}(t)\right)^{2}}{1,000+v(t)+v^{\prime}(t)}\right]}\right. \\
& g\left(t, u(t), u^{\prime}(t)\right)=\left[1+\left(t-\frac{3}{4}\right)^{2}\right]\left[\frac{100\left(u(t)+u^{\prime}(t)\right)}{\left.e^{200\left(u(t)+u^{\prime}(t)\right)}+\frac{100\left(u(t)+u^{\prime}(t)\right)^{2}}{1,000+u(t)+u^{\prime}(t)}\right] .}\right.
\end{aligned}
$$

It is easy to compute that $f_{0}=\frac{200}{7}, f_{\infty}=\frac{200}{7}, g_{0}=100, g_{\infty}=100$ and $g^{0}=\frac{625}{4}$, which show that $A_{2} f_{0}>1, A_{2} f_{\infty}>1, B_{2} g_{0}>1, B_{2} g_{\infty}>1$ and $B_{2} g^{0}<2$.

Choose $\mu=14$,

$$
\begin{aligned}
& \max \{g(t, x, y), t \in[0,1],(x+y) \in[0,14]\}=\frac{50}{e}+\frac{4,900}{507}<29<\frac{2 \mu}{B_{1}} \\
& \max \{f(t, x, y), t \in[0,1],(x+y) \in[0,14]\}=\frac{25}{16}\left(\frac{1}{2 e}+\frac{9,800}{507}\right)<21<\frac{\mu}{2 A_{1}} .
\end{aligned}
$$

So, it follows from Theorem 3.3 that BVP (4.1) has at least two positive solutions.

\section{Competing interests}

The author declares that she has no competing interests.

\section{Author's contributions}

The author read and approved the final manuscript.

\section{Acknowledgements}

The work is supported by the Science and Technology Foundation of Hebei Province (Z2013016) and the Science and Technology Plan Foundation of Tangshan (12110233b) and the Scientific Research Foundation of Tangshan College (13011B). The author would like to thank the anonymous referees very much for helpful comments and suggestions which led to the improvement of presentation and quality of the work.

\section{Received: 8 December 2013 Accepted: 6 March 2014 Published: 21 Mar 2014}

\section{References}

1. Webb, JRL, Infante, G: Positive solutions of nonlocal boundary value problems: a unified approach. J. Lond. Math. Soc 74(2), 673-693 (2006)

2. Webb, JRL, Infante, G: Nonlocal boundary value problems of arbitrary order. J. Lond. Math. Soc. 79(2), 238-258 (2009)

3. Webb, JRL: Positive solutions of some higher order nonlocal boundary value problems. Electron. J. Qual. Theory Differ. Equ. 29, 1-15 (2009)

4. Boucherif, A, Bouguima, SM, Al-Malki, N, Benbouziane, Z: Third order differential equations with integral boundary conditions. Nonlinear Anal. 71, e1736-e1743 (2009) 
5. Du, Z, Ge, W, Zhou, M: Singular perturbations for third-order nonlinear multi-point boundary value problem. J. Differ. Equ. 218, 69-90 (2005)

6. El-Shahed, M: Positive solutions for nonlinear singular third order boundary value problems. Commun. Nonlinear Sci. Numer. Simul. 14, 424-429 (2009)

7. Graef, JR, Webb, JRL: Third order boundary value problems with nonlocal boundary conditions. Nonlinear Anal. 71, 1542-1551 (2009)

8. Graef, JR, Yang, B: Positive solutions of a third order nonlocal boundary value problem. Discrete Contin. Dyn. Syst., Ser. S 1, 89-97 (2008)

9. Henderson, J, Tisdell, CC: Five-point boundary value problems for third-order differential equations by solution matching. Math. Comput. Model. 42, 133-137 (2005)

10. Hopkins, B, Kosmatov, N: Third-order boundary value problems with sign-changing solutions. Nonlinear Anal. 67 126-137 (2007)

11. Ma, R: Multiplicity results for a third order boundary value problem at resonance. Nonlinear Anal. 32, 493-499 (1998)

12. Sun, JP, Li, HB: Monotone positive solution of nonlinear third-order BVP with integral boundary conditions. Bound. Value Probl. 2010, Article ID 874959 (2010). doi:10.1155/2010/874959

13. Zhao, JF, Wang, PG, Ge, WG: Existence and nonexistence of positive solutions for a class of third order BVP with integral boundary conditions in Banach spaces. Commun. Nonlinear Sci. Numer. Simul. 16, $402-413$ (2011)

14. Zhang, HE, Sun, JP: Existence and iteration of monotone positive solutions for third-order nonlocal BVPs involving integral conditions. Electron. J. Qual. Theory Differ. Equ. 18, 1-9 (2012)

15. Du, ZJ: Singularly perturbed third-order boundary value problem for nonlinear systems. Appl. Math. Comput. 189(1), 869-877 (2007)

16. Henderson, J, Luca, R: On a system of higher-order multi-point boundary value problems. Electron. J. Qual. Theory Differ. Equ. 49, 1-14 (2012)

17. Henderson, J, Luca, R: Positive solutions for a system of second-order multi-point boundary value problems. Appl. Math. Comput. 218, 6083-6094 (2012)

18. Infante, G, Pietramala, P: Eigenvalues and non-negative solutions of a system with nonlocal BCs. Nonlinear Stud. 16, 187-196 (2009)

19. Infante, G, Pietramala, P: Existence and multiplicity of non-negative solutions for systems of perturbed Hammerstein integral equations. Nonlinear Anal. 71, 1301-1310 (2009)

20. Infante, G, Minhós, FM, Pietramala, P: Non-negative solutions of systems of ODEs with coupled boundary conditions. Commun. Nonlinear Sci. Numer. Simul. 17, 4952-4960 (2012)

21. Infante, G, Pietramala, P: Multiple positive solutions of systems with coupled nonlinear BCs. arXiv:1306.5556

22. Li, YH, Guo, YP, Li, GG: Existence of positive solutions for systems of nonlinear third-order differential equations. Commun. Nonlinear Sci. Numer. Simul. 14, 3792-3797 (2009)

23. Li, SJ, Zhang, XG, Wu, YH, Caccetta, L: Extremal solutions for $P$-Laplacian differential systems via iterative computation. Appl. Math. Lett. 26(12), 1151-1158 (2013)

24. Li, WT, Sun, JP: Multiple positive solutions of BVPs for third-order discrete difference systems. Appl. Math. Comput. 149, 389-398 (2004)

25. Jankowski, T: Nonnegative solutions to nonlocal boundary value problems for systems of second-order differential equations dependent on the first-order derivatives. Nonlinear Anal. 87, 83-101 (2013)

26. Wang, GW, Zhou, MR, Sun, L: Existence of solutions of boundary value problem for 3rd order nonlinear system. Appl. Math. Comput. 189,1131-1138 (2007)

27. Yang, Z: Positive solutions to a system of second-order nonlocal boundary value problems. Nonlinear Anal. 62, 1251-1265 (2005)

28. Zhang, HE, Sun, JP: Existence of positive solution to singular systems of second-order four-point BVPs. J. Appl. Math. Comput. 29, 325-339 (2009)

29. Zhong, Y, Chen, SH, Wang, CP: Existence results for a fourth-order ordinary differential equation with a four-point boundary condition. Appl. Math. Lett. 21, 465-470 (2008)

10.1186/1687-2770-2014-61

Cite this article as: Zhang: Multiple positive solutions of nonlinear BVPs for differential systems involving integral conditions. Boundary Value Problems 2014, 2014:61

\section{Submit your manuscript to a SpringerOpen ${ }^{\odot}$ journal and benefit from:}

- Convenient online submission

- Rigorous peer review

- Immediate publication on acceptance

- Open access: articles freely available online

- High visibility within the field

- Retaining the copyright to your article 